\title{
Animales y enseñanza
}

Keywords: Animales y enseñanza; enseñanza en el respeto animal; Derecho Animal; Derecho del Bienestar Animal

La enseñanza en el respeto por los animales es la clave para cualquier reforma que nos queramos plantear en el futuro. El Derecho juega en este ámbito un papel indispensable para regular mejor las relaciones de una sociedad, comprometida con el futuro del entorno en el que se desenvuelve.

Hablo de animales y no del "animal", como si fuera un ente de razón. Me refiero a los animales con los que compartimos nuestro entorno y con los que, mantenemos diferentes tipos de relación, con algunos de verdadera proximidad, como los animales de compañía, pero también con los de producción, con la fauna salvaje o con los animales que intervienen en los espectáculos o en la experimentación.

Cuando hablamos de respeto por los animales, a qué nos referimos?, qué implica dentro de la sociedad actual?, a qué nos obliga como individuos, como sociedad, como miembros de un Estado de Derecho?. Qué estrategias hay que usar, para hacer realidad el respeto por los animales?.

Respeto es conocimiento y reconocimiento de la singularidad de alguien. Es conocimiento, primera premisa, y es aceptación de su valor y dignidad intrínseca [1]. En la práctica, consiste en algo tan simple como valorar los intereses que a alguien le son propios, la aceptación de los mismos y la salvaguarda de dichos intereses. Por lo tanto, el respeto, en relación con los animales, parte de una mejora del conocimiento de su naturaleza, de su singularidad, de su dignidad, de sus intereses y de la salvaguarda y protección de los mismos. Este es el principio inspirador de un grupo de trabajo, del que formo parte, radicado en París, que está dedicado a la búsqueda de nuevas formas de incluir el respeto por los animales dentro de los planes de enseñanza [2].

Independientemente de que nos "gusten" los animales o no, forman parte de nuestra sociedad. Lo he dicho de forma consciente: son parte de nuestra sociedad. Durante siglos, quizá, se ha podido vivir de espaldas a la realidad de que compartimos un mismo entorno vital, pero los conocimientos científicos, desde hace ya largo tiempo, nos están poniendo ante los ojos dos datos que tienen gran relevancia: que los animales tienen una cultura propia y que tienen una sensibilidad ante el dolor como la nuestra. Si nos preguntamos a cúantos de nuestros conciudadanos les resulta "natural" asumir estos dos datos, el resultado puede ser descorazonador. Sin embargo, aún sin saberlo explicitar, cada vez más, la sociedad demanda una nueva conciencia favorable a los animales. Una actitud de respeto público por los animales. Por lo tanto, para vencer esa aparente contradicción -demanda de una mejora de la situación de los animales, efectiva inserción de políticas públicas para lograrlo e ignorancia de por qué realmente se debe de asumir este reto-, la clave es la enseñanza.

Introducir en todos los niveles de la enseñanza el respeto por los animales y cómo regular su inserción en la sociedad actual, es una consecuencia directa de que el Estado asuma su papel de regulador de las necesidades y demandas de la sociedad. Se trata de introducir cursos de formación para el Profesorado y cursos específicos en cada nivel de la enseñanza incluyendo, claro es, las enseñanzas profesionales y la enseñanza universitaria.

Hace unos meses, el Ayuntamiento de Amsterdam publicó un documento muy revelador, de cómo la mejora de las políticas públicas en favor de los animales, había hecho descender la violencia y la agresividad en el entorno social. Holanda es uno de los países pioneros en la creación de una "hot line" de socorro ante el maltrato animal y de un cuerpo de policía específico y formado en rescate de animales 
maltratados. Es un ejemplo, entre muchos, de qué consecuencias tiene una efectiva política pública de enseñanza en la protección y respeto por los animales.

LA EDITORA

Teresa Giménez-Candela Catedrática de Derecho Romano

Animal Law Profesor

Universitat Autònoma de Barcelona

[1] Vid. Vid. HALL, B., Reseña bibliográfica de Adela Cortina, Las fronteras de la persona. El valor de los animales, la dignidad de los humanos

[2] Vid. BRELS, S., Table ronde sur l' "Animal et l'enseignement", Palais du Luxembourg à Paris, 16 décembre 2013 